\title{
Diazinon-Induced Clastogenity and Pathological Changes in Ovaries and Testes of Clarias gariepinus
}

\author{
Olufunke Eunice Ola-Davies' ${ }^{1}$ Adekemi Florence Fagbohun ${ }^{2 *}$, \\ Benjamin Obukowho Emikpe ${ }^{3}$, Olanike Kudirat Adeyemo ${ }^{2}$ \\ ${ }^{1}$ Department of Veterinary Physiology, Biochemistry and Pharmacology, University of Ibadan, Ibadan, Nigeria \\ ${ }^{2}$ Fish and Wildlife Unit, Department of Veterinary Public Health and Preventive Medicine, University of Ibadan, \\ Ibadan, Nigeria \\ ${ }^{3}$ Department of Veterinary Pathology, University of Ibadan, Ibadan, Nigeria \\ Email: ${ }^{\text {fagbohunadekemi@gmail.com }}$
}

Received 11 December 2014; accepted 31 December 2014; published 24 January 2015

Copyright (C) 2015 by authors and Scientific Research Publishing Inc.

This work is licensed under the Creative Commons Attribution International License (CC BY). http://creativecommons.org/licenses/by/4.0/

(c) (i) Open Access

\section{Abstract}

In most tropical developing countries, one of the problems facing aquaculture industry is the pollution of ponds and rivers with pesticides. Chemicals such as diazinon, an organophosphate pesticide, originating from agricultural activity enter the aquatic environment through atmospheric deposition, surface run-off or leaching. Pollutants enter the food chain through accumulation in soft bottom sediment and aquatic organisms. However, information on how these pesticides affect inhabiting organisms is often not available. In a triplicate experimental set-up, seventy-two (72) apparently healthy catfish comprising adult and juvenile of both sexes were therefore exposed to a previously determined no effect concentration $(0.405 \mathrm{ppm})$ of diazinon. Another set of fish was exposed to $0.0625 \mu \mathrm{g}$ sodium arsenite, a known clastogen, which was used as the positive control, while another set of catfish exposed to the culture water alone was the negative control. Adults and juveniles were exposed separately to avoid cannibalism. After 48 hours of exposure, micronuclei induction was determined in subsets of experimental groups, while exposure continued for 28 days. Catfish organs were harvested on days 21 and 28 to determine the effect of long-term exposure to diazinon on histology. Water quality was also monitored before and during exposure in the experimental groups. The result established a significantly high mean micronucleated polychromatic erythrocytes $(15.00)$ in catfish exposed to diazinon suggesting genetic damage (normal is $\leq 4)$. The MPE in sodium arsenite exposed fish was 28, while that of the control group was below 4 . Effect of sex and age on micronuclei induction was not significant. Histological alteration observed in the ovary and testis was distorted matured cells and extensive testicular degeneration, respectively. The results show that diazinon has clastogenic effect, and may have endocrine disrupting properties because of the histological changes induced in the ovaries and testis.

\footnotetext{
"Corresponding author.
} 


\section{Keywords}

\section{Catfish, Diazinon, Clastogenicity, Aquaculture}

\section{Introduction}

Catfish have inhabited all continents at one time or another [1]. Catfish are most diverse in tropical South America, Africa and Asia [2]. Clarias gariepinus is hardy and does not easily succumb to disease; it has a high capacity to attain massive growth depending on the species being bred. In most developing countries, one of the problems facing aquaculture industry is the pollution of ponds and rivers with pesticides such organophosphate chlorinated pesticides [3]. Although they are useful tools in agriculture, forestry and in veterinary medicine, their contribution to the general degradation of the aquatic ecosystem cannot be ignored [4] and not all their effects on fish have evaluated. Organophosphate pesticides have fully replaced the persistent chlorinated pesticide in the 1970s and in the beginning of 1980s the main advantage of the organosphosphate pesticide was their low cumulative ability and short-term persistence in the environment; although the organophosphate pesticides have been replaced by pyrethroid based pesticides, there is still very intensive use of the organophosphate [5]. For example, diazinon is used on home gardens and farm to control a wide variety of suckling and leaf eating insects. It is also used in rice, fruits, tress, sugarcane, corn, tobacco, potatoes, cocoa and horticultural plants. Organophosphate pesticides are used in fish culture in order to suppress some parasitic diseases nevertheless, the pesticide preparations are considered harmful to fish in most cases [5]. In all parts of the world, pesticides have been found in the aquatic ecosystem and also enter the food chain. Often, information on how these pesticides affect inhabiting organisms is not available [6]. This study therefore undertakes to assess the acute effect of diazinon on micronuclei induction and chronic effect on histological changes in the gonads of Clarias gariepinus.

\section{Methodology}

Seventy two (72) apparently healthy adult and juvenile catfish (Clarias gariepinus) of both sexes were set up in triplicate, adults and juveniles were exposed separately to avoid cannibalism. Five (5) catfish each (adult \& Juvenile) male and female were exposed to different treatment which includes pre-determined no effect concentration $(0.405 \mathrm{ppm})$ of diazinon, positive control of environmentally relevant concentration $(0.0625 \mu \mathrm{g} / \mathrm{L})$ of sodium arsenite; a known clastogen, while negative control samples were exposed to culture water only. Route of exposure was via culture water. For each group, samples were collected on days 21 and 28 for histology which is the specify days for most chronic effects of fish in aquaculture (organs collected were ovaries and testes). The slices were stained by Hematoxylin-Eosin (H \& E).

\section{Micronucleus Assay}

Genotoxic effects were evaluated in peripheral blood using micronuclei test described by [7] with some modifications. Blood were collected from living fish specimens in experimental group between twenty four (24) and forty eight (48) hours through the caudal veins using $2 \mathrm{G}$ needles and syringes. Immediately after blood collections, thin, uniform blood smears were prepared on clean microscopic slides and air-dried. The slides were fixed in methanol and later stained in May-Grunnwald. Slides were mounted in DPX mountant, dried $\left(20^{\circ} \mathrm{C}-30^{\circ} \mathrm{C}\right)$, cleaned and properly coded. The frequencies of micronuclei (MN) in polychromatic erythrocytes (PCE) were estimated by scoring 1000 PCE per animal.

\section{Results}

\section{Micronucleus Induction}

The mean micronucleated polychromatic erythrocyte in catfish exposed to diazinon was $15 \pm 0.00$ ), sodium arsenite was $28 \pm 0.00$ ) while that of the negative control group (cultured water only was $10 \pm 0.00$ ) as shown in Table 1. Data were subjected to analysis of variance of SAS 2004 [8] at significantly different $(\mathrm{p}<0.05)$. 


\section{Histopathology}

The group exposed to the no effect concentration $(0.405 \mathrm{ppm})$ of diazinon had distorted mature ovarian cells as shown in Figure 2 when compared with Figure 3 the normal ovary and the testes had locally extensive testicular degeneration as shown Figure 4 when compared with Figure 5 the normal testis.

\section{Discussion}

At present, more than 1000 chemicals have been classified as pesticides and studies using different models have indicated that some of them have genotoxic properties [9].

Fish and aquatic invertebrates have been considered to be efficient and cost effective model system for study-

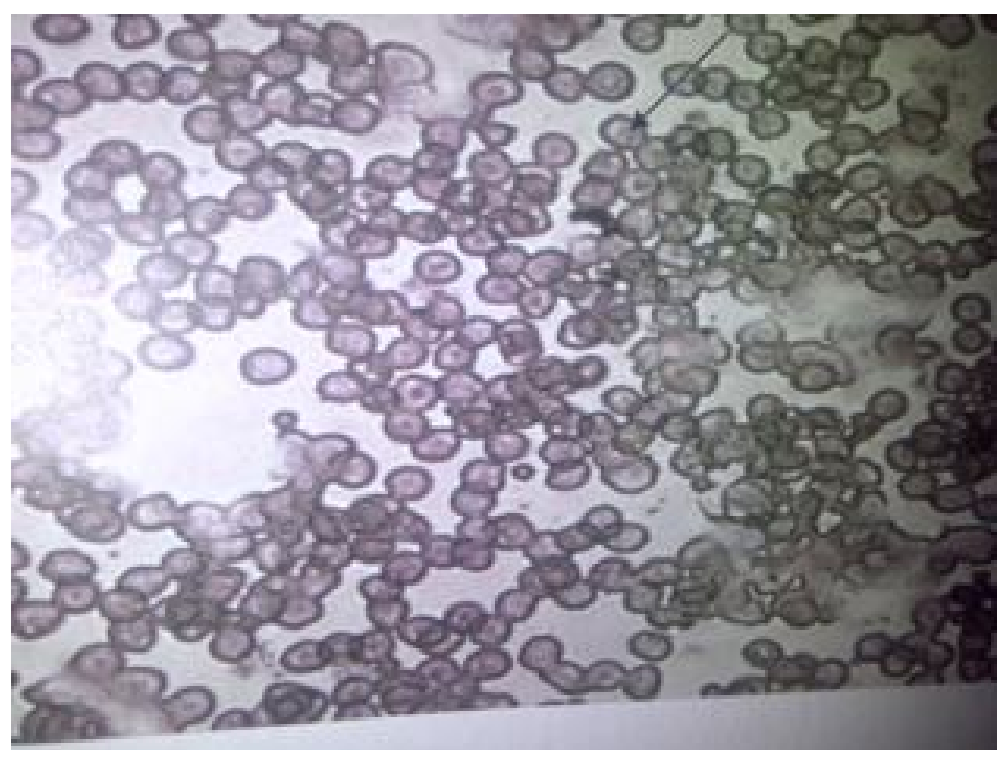

Figure 1. Photomicrograph of an adult female catfish blood exposed to diazinon with an arrow showing a micronucleated polychromatic erythrocytes cells (May-Grunnwald ×400).

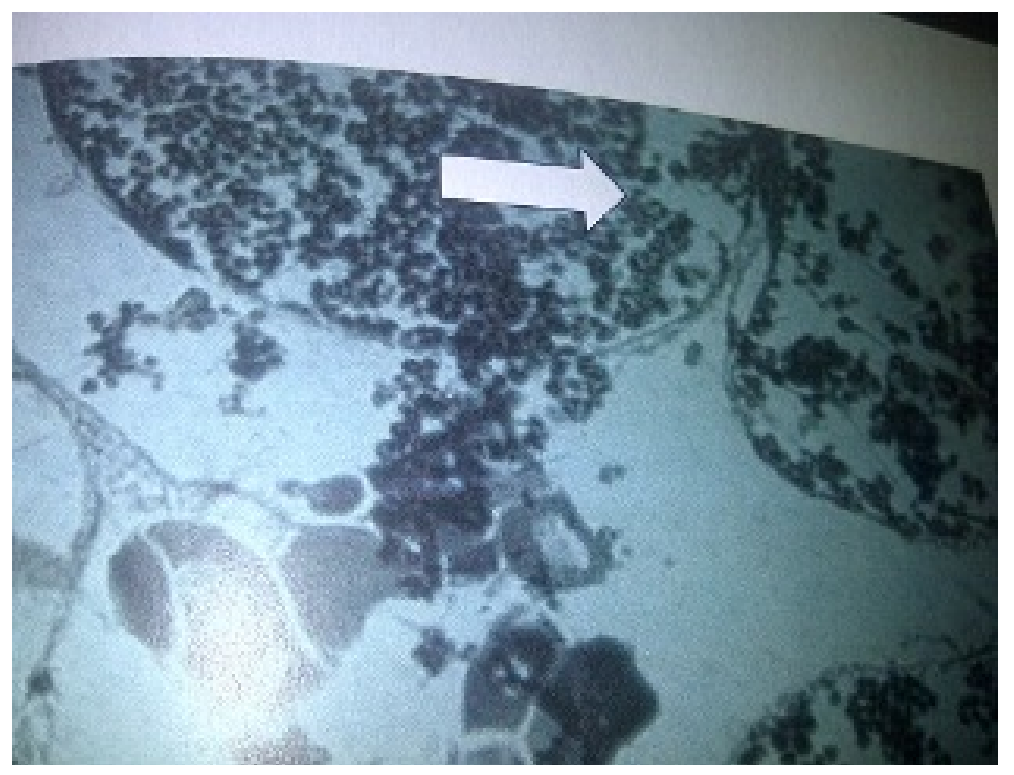

Figure 2. Photomicrograph of the ovary with arrow showing distorted matured cells (H \& E) M: $\times 400$ (At 28 days of exposure). 


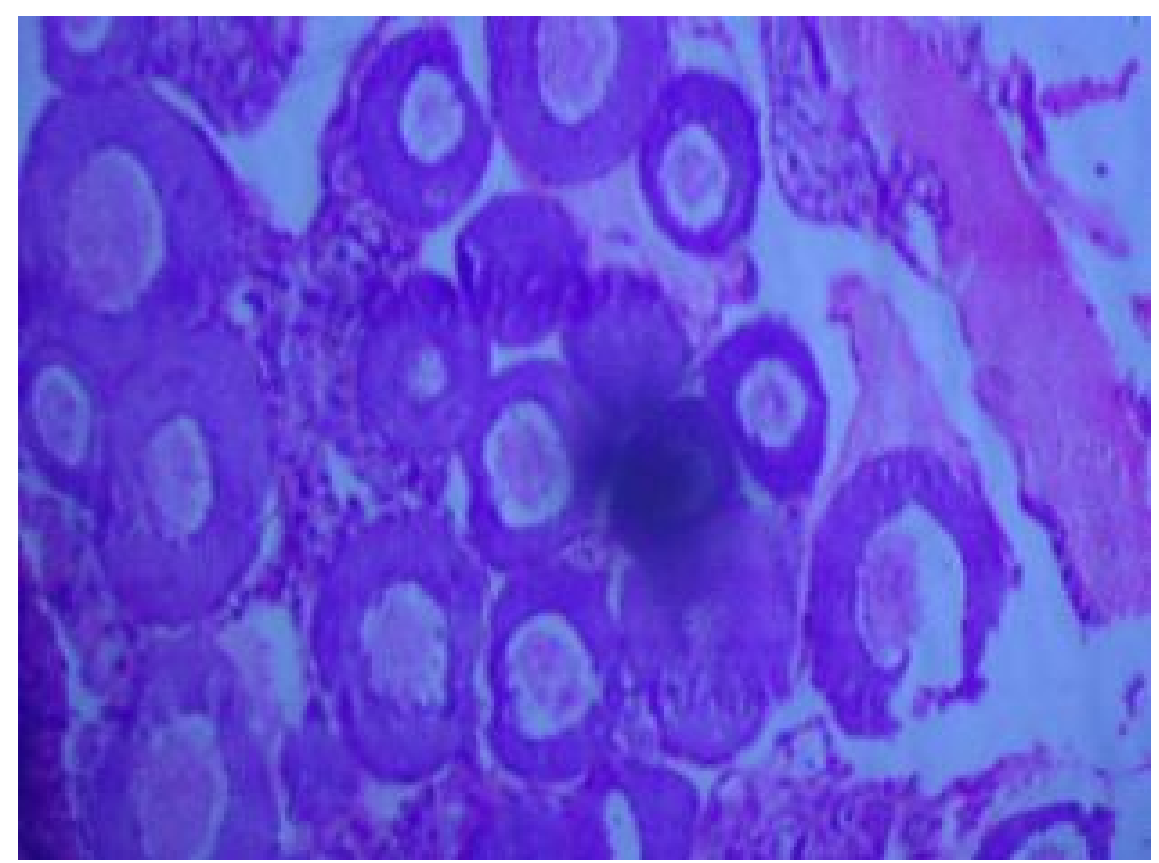

Figure 3. Photomicrograph of a normal ovary $(\mathrm{H} \& \mathrm{E}) \mathrm{M}: \times 400$.

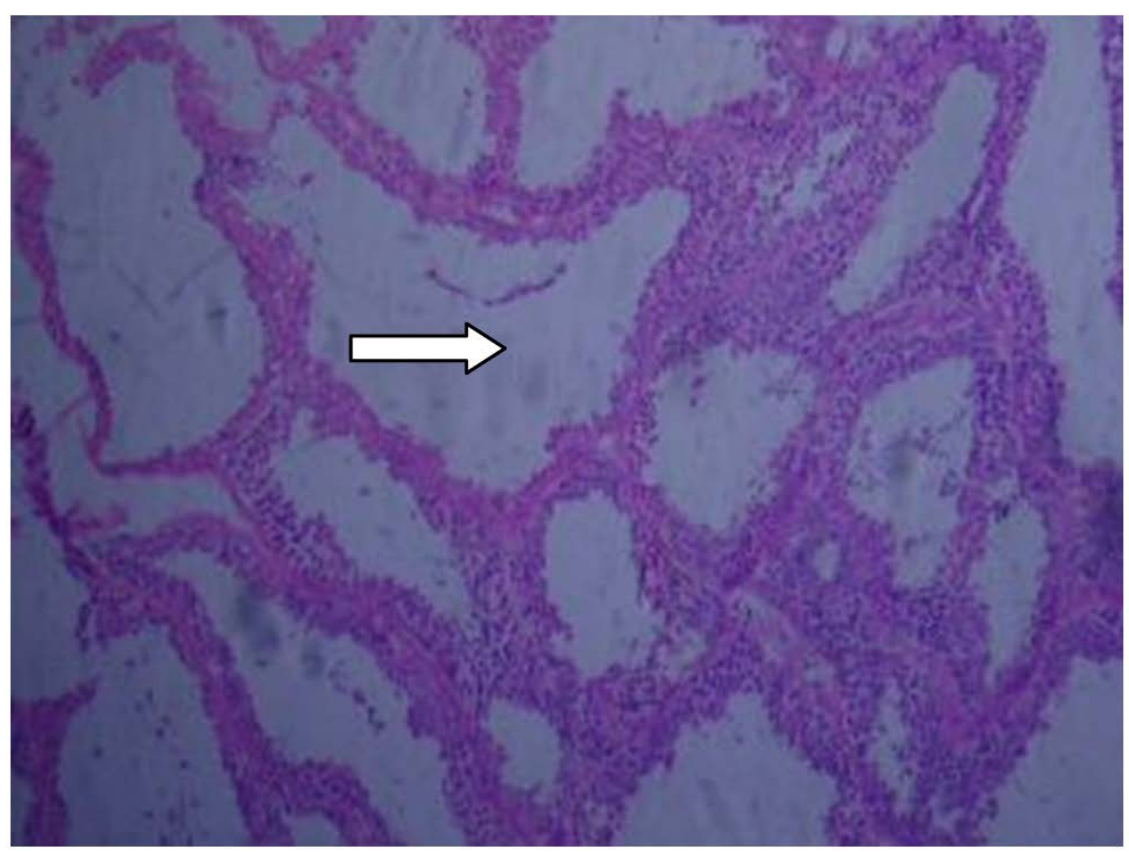

Figure 4. Photomicrograph of the testis with arrow showing extensive testicular degeneration (H \& E) M: $\times 400$ (At 28 days of exposure).

Table 1. The frequency of micronucleated PCE/1000 PCE in catfish blood cells following administration of test substances.

\begin{tabular}{|cccccccccccccc}
\hline & \multicolumn{3}{c}{ Diazinon exposed } & \multicolumn{3}{c}{ Sodium-arsenite exposed (positive control) } & \multicolumn{3}{c}{ Control (exposed to cultured water) } \\
\hline $\begin{array}{c}\text { Adult } \\
\text { male }\end{array}$ & $\begin{array}{c}\text { Adult } \\
\text { female }\end{array}$ & $\begin{array}{c}\text { Juvenile } \\
\text { Male }\end{array}$ & $\begin{array}{c}\text { Juvenile } \\
\text { female }\end{array}$ & $\begin{array}{c}\text { Adult } \\
\text { male }\end{array}$ & $\begin{array}{c}\text { Adult } \\
\text { female }\end{array}$ & $\begin{array}{c}\text { Juvenile } \\
\text { male }\end{array}$ & $\begin{array}{c}\text { Juvenile } \\
\text { female }\end{array}$ & $\begin{array}{c}\text { Adult } \\
\text { male }\end{array}$ & $\begin{array}{c}\text { Adult } \\
\text { female }\end{array}$ & $\begin{array}{c}\text { Juvenile } \\
\text { male }\end{array}$ & $\begin{array}{c}\text { Juvenile } \\
\text { female }\end{array}$ \\
\hline
\end{tabular}

$14.67 \pm 0.0015 .00 \pm 0.0015 .67 \pm 1.1516 .53 \pm 1.1528 .00 \pm 0.0028 .00 \pm 0.0028 .00 \pm 0.00 \quad 28.67 \pm 0.0010 .00 \pm 0.009 .33 \pm 0.00 \quad 8.67 \pm 0.00 \quad 9.33 \pm 0.00$

Sex and age of catfish did not have significant effect on micronuclei induction. 


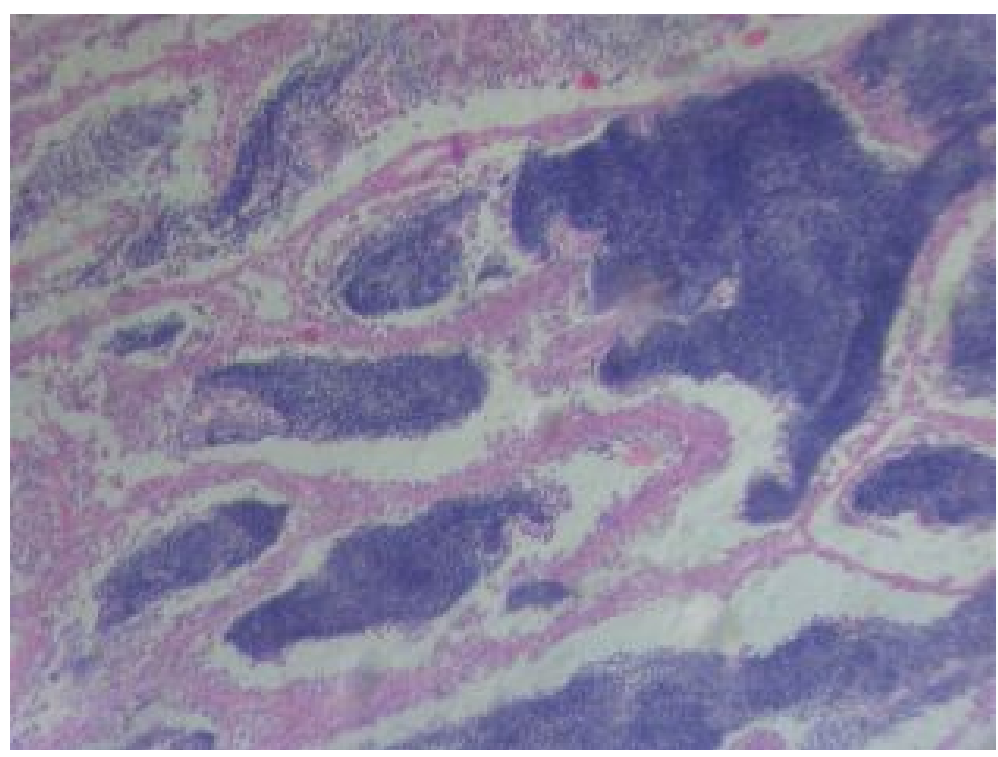

Figure 5. Photomicrograph of a normal testis $(H \&$ E) M: $\times 400$.

ing the toxic, mutagenic, and carcinogenic potential of pollutants [10]-[13] due to their ability to metabolise, concentrate, and store water-borne pollutants [14].

The clastogenic effects of chemical agents on fish cells compared with that of a known clastogen sodium arsenite was demonstrated with emphasis on the induction of micronuclei in polychromatin erythrocytes. The result obtained in this experiment indicated that sodium arsenite had the highest number of micronucleated polychromatic erythrocyte (PCE)/1000 PCE $(28.00 \pm 0.00)$ which is the positive control (Table 1). This is confirming that sodium arsenite is highly clastogenic which is in line with the report of [15]-[17]. While that of the of the tested group diazinon (15.00 \pm 0.00$)$ as compared with the sodium arsenite group, suggesting genetic damage. Effect of sex and age on micronuclei induction is not significant; however more immature erythrocytes were seen in Juvenile groups than in the adult groups.

The exposure of fish to chemical contaminants is likely to induce a number of lesions in different organs [18]. Histology is an important tool to investigate changes at cellular level like the endocrine disrupting effects of diazinon on fish. It is believed that diazinon is one of the most harmful organophosphate that could be as Endocrine Disrupting Chemicals (EDCs) and suppress reproductive activities with endogenous hormonal disruption [19]-[21]. It also could have direct effects on gonads, disrupting sexual behaviours, gemates quality and spawning process.

\section{Conclusions}

The clastogenic effects of chemical agents on fish cells compared with that of a known clastogen (sodium arsenite) were demonstrated with emphasis on the induction in micronuclei in polychromatic erythrocytes (PCE). The result obtained in this experiment indicated that sodium arsenite had the highest PCE (28), affirming that sodium arsenite is highly clastogenic (positive control) and those exposed to test group diazinon (15) suggestive of genetic damage when the normal is supposed to be $\leq 4$.

This study showed histopathological changes in ovary and testis of catfish exposed to low level of diazinon, indicative of diazinon having a detrimental effect on the cellular integrity of the reproductive organs. Therefore, in culturing, these could lead to poor performance, reduced productivity, compromised immune status and may eventually lead to death of the fish.

A stringent control of the use of diazinon is hereby recommended to forestall adverse impact on feral and cultured fish.

\section{References}

[1] Nelson, J.S. (2006) Fishes of the World. John Wiley \& Sons, Inc., Hoboken. 
[2] Lungberg, J.G. and Friel, J.P. (2003) Siluriformes. Tree of Life Web Project. http://tolweb.org/tree/group=Siluriformes\&contgroup=Ostariophysi

[3] Alabaster, J.S. (1981) Review of the State of Aquatic Pollution of East African Inland Waters. CIFA Occasional Paper No. 9, 36 p.

[4] Konar, S.K. (1975) Pesticides and Aquatic Ecosystem. Indian Journal of Fisheries, 22, 1-2.

[5] Robert and Hutson (1998) Metabolic Pathways of Agrochemical Parts 2; Insecticides and Fungicides. The Royal Society of Chemistry, Cambridge, 1475 p.

[6] Castillo, L.E. and Ruepert, C. (2000) Pesticide Residue in the Aquatic Environment of Banana Plantation Areas in the North Atlantic Zone of Coast Rica. Journal Environmental Toxicology and Chemistry, 19, 1942-1950. http://dx.doi.org/10.1002/etc.5620190802

[7] Holland, N., Bolognesi, C., Kirsh-Volders, M., Bonassi, S., Zeiger, E. and Knassmueller, S. (2008) The Micronucleus Assay in Human Buccal Cells as a Tool for Biomonitoring DNA Damage: The HUMN Project Perspective on Current Status and Knowledge Gaps. Mutation Research, 659, 93-108. http://dx.doi.org/10.1016/j.mrrev.2008.03.007

[8] SAS (2004) SAA/STAT. User’s Guide (Release 8.03). SAS Institute, Cary, North Carolina.

[9] Zeljezic, D. and Garaj-Vrhovac, V. (2002) Sister Chromatid Exchange and Proliferative Rate Index in the Longitudinal Risk Assessment of Occupational Exposure to Pesticides. Chemosphere, 46, 295-303. http://dx.doi.org/10.1016/S0045-6535(01)00073-X

[10] Belpaema, K., Delbeke, K., Zhu, L. and Kirsch-Volders, M. (1996) Cytogenic Studies of PCB77 on Brown Trout (Salmo trutta fario) Using the Micronucleus Test and the Alkaline Comet Assay. Mutagenesis, 11, 485-492. http://dx.doi.org/10.1093/mutage/11.5.485

[11] Braunbeck, T., Boettcher, M., Hollert, H., Kosmehi, T., Lammer, E., Leist, E., Rudolf, M. and Seitz, N. (2005) Towards an Alternative for the Acute Fish LC(50) Test in Chemical Assessment: The Fish Embryo Toxicity Test Goes Multi-Species-An Update. ALTEX, 22, 87-102.

[12] Muller, W.E.G., Ed. (1994) Use of Aquatic Invertebrates as Tools for Monitoring of Environmental Hazards. Gustav Fischer Verlag, Stuttgart.

[13] Spitsbergen, J.M. and Kent, M.L. (2003) The State of the Art of the Zebrafish Model for Toxicology and Toxicologic Pathology Research-Advantages and Current Limitations. Toxicologic Pathology, 31, 62-87.

[14] Osman, A.G.M., Wuertz, S., Mekkawy, I.A., Exner, H.J. and Kirschbaum, F. (2007) Lead Induced Malformations in Embryos of the African Catfish Clarias gariepinus (Burchell, 1822). Environmental Toxicology, 22, 375-389.

[15] Yang, H., Shum, A.Y.C., Ng, H.T. and Chen, C.F. (1986) Effect of Ethanol on Human Umbilical Artery and Vein in Vitro. Gynecologic and Obstetric Investigation, 21, 131-135. http://dx.doi.org/10.1159/000298942

[16] Guzzo, A., Karatzois, C., Diorio, C. and Dubow, M.S. (1994) Methallothioren II and Ferritin H mRNA Levels Are Increased in Arsenite Exposed HeLa Cells. Biochemical and Biophysical Research Communications, 205, 590-595. http://dx.doi.org/10.1006/bbrc.1994.2706

[17] Wang, T.S., Kuo, C.F., Jan, K.Y. and Huang, H. (1996) Arsenite Induce Apoptosis in Chinese Hamster Ovary Cells by Generation of Reactive Oxygen Species. Journal of Cellular Physiology, 169, 256-268. http://dx.doi.org/10.1002/(SICI)1097-4652(199611)169:2<256::AID-JCP5>3.0.CO;2-N

[18] Bucke, D., Vethannk, D., Lang, T. and Mellergaard, S. (1996) Common Diseases and Parasites of Fish in the North Atlantic: Training Guide for Identification. International Council for the Exploration of the Sea Techniques in Marine Environmental Sciences, Copenhagen.

[19] Dutta, H.M. and Arends, D. (2003) Effects of Endosulfan on Brain Acetylcholinesterase Activity in Juvenile Bluegill Sunfish. Environmental Research, 91, 157-162. http://dx.doi.org/10.1016/S0013-9351(02)00062-2

[20] Xue, N., Xu, X. and Jin, Z. (2005) Screening 31 Endocrine-Disrupting Pesticides in Water and Surface Sediment Samples from Beijing Guanting Reservoir. Chemosphere, 61, 1594-1606. http://dx.doi.org/10.1016/j.chemosphere.2005.04.091

[21] Mlambo, S.S., van Vuren, J.H.J., Barnhoorn, I.E.J. and Bornman, M.S. (2009) Histopathological Changes in the Reproductive System (Ovaries and Testes) of Orechromis mossambicus Following Exposure to DDT. Environmental Toxicology and Pharmacology, 28, 133-139. http://dx.doi.org/10.1016/j.etap.2009.03.011 
Scientific Research Publishing (SCIRP) is one of the largest Open Access journal publishers. It is currently publishing more than 200 open access, online, peer-reviewed journals covering a wide range of academic disciplines. SCIRP serves the worldwide academic communities and contributes to the progress and application of science with its publication.

Other selected journals from SCIRP are listed as below. Submit your manuscript to us via either submit@scirp.org or Online Submission Portal.
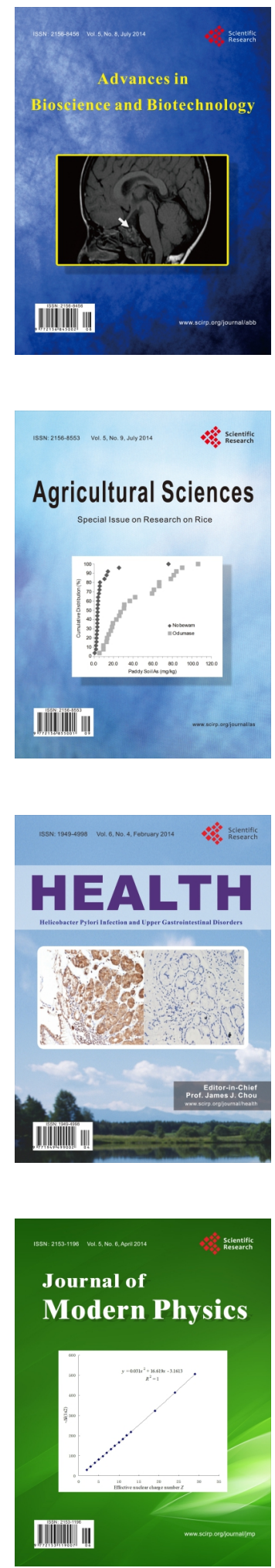
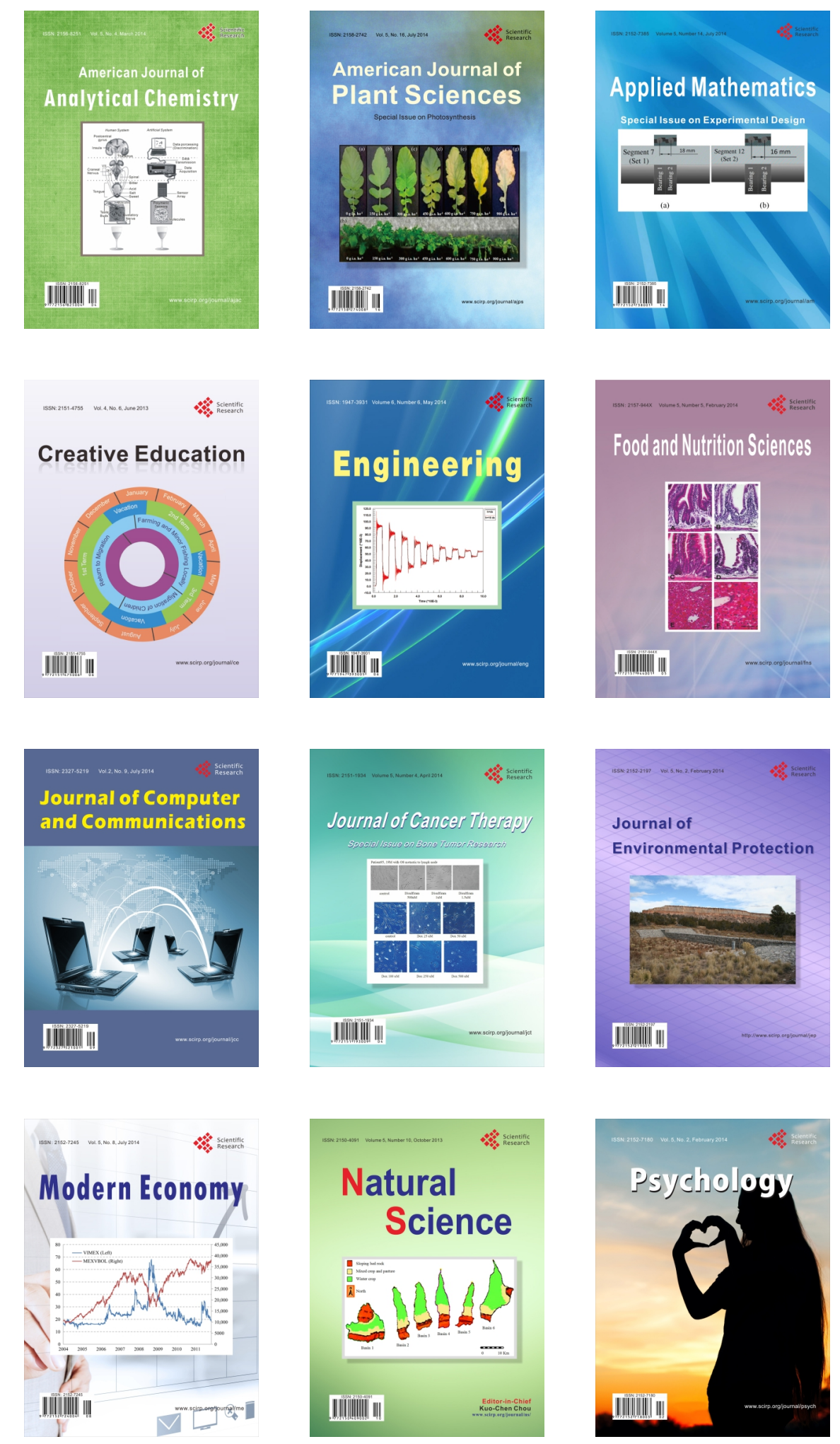